\section{Simulated Particle and Vapor Drift of Dicamba to 'Vidal blanc' Hybrid Grapevine under Missouri Field Conditions}

\author{
Sarah E. Dixon ${ }^{1}$, Jerri L. Henry ${ }^{2}$, Dean S. Volenberg ${ }^{1}$, and \\ Reid J. Smeda ${ }^{1}$
}

\begin{abstract}
AdDitional INDEX WORDs. auxin, herbicide, injury, pesticide, residue, Vitis
SUMMARY. The increasing adoption of dicamba-tolerant soybean (Glycine max) increases the potential exposure of wine grape (Vitis sp.) to dicamba, to which off-target injury may occur via particle drift or vapor drift. In Missouri, at one site in 2017 and at two sites in 2018 , research of production vineyards focused on the effects of dicamba on hybrid 'Vidal blanc' grapevines. During flowering and early fruit set, bearing grapevines were exposed to low rates of dicamba delivered as a spray solution of 81 or $161 \mathrm{ppm}$ or by vapor from treated soil. Grapevines were highly sensitive to dicamba, and visible symptoms extended throughout the growing season. The severity of dicamba injury (leaf cupping and feathering) was similar at two of three site-years, with greater injury related to particle drift than to vapor drift of dicamba. Early-season injury resulted in dicamba impacting the total soluble solids (TSS) content of grape berries and grape yield. At harvest during two site-years, yield reductions of up to $45 \%$ were associated with dicamba exposure at flowering. Across all site-years, no significant effects of dicamba drift were observed in the TSS content of berries during veraison in August, as measured by refractometer. However, the final TSS content of berries at harvest in September was reduced by $12 \%$ from dicamba as particle drift. At a minimum detection level of $10 \mathrm{ng} \cdot \mathrm{mL}^{-1}$, high-performance liquid chromatography mass spectrometry identified dicamba at levels up to 33 $\mathrm{ng} \cdot \mathrm{mL}^{-1}$ in grape must over all site-years. Unexpectedly, this was up to $125 \mathrm{~d}$ after grapevine exposure despite low levels of visible dicamba symptomology.
\end{abstract}

$\mathrm{P}$ lant growth regulator herbicides such as dicamba are used for selective control of many broadleaf weed species. The introduction of dicamba-tolerant (DT) soybean (Glycine max) and cotton (Gossypium birsutum) in 2016 and the increase in glyphosate-resistant weed species (Heap, 2019) have driven the increased

Received for publication 29 Mar. 2021. Accepted for publication 20 Aug. 2021

Published online 12 October 2021.

${ }^{1}$ Division of Plant Sciences, University of Missouri, Waters Hall, 1112 University Avenue, Columbia MO 65201

${ }^{2}$ Syngenta Crop Protection, Inc., 410 Swing Road, Greensboro, NC 27409

We thank the Missouri Wine and Grape Board as well as the Missouri Grape and Wine Institute for financial support of this research. We also thank Cory Bomgaars, Paul Hopen, Tony Kooyumjian, Shawna Mull, Shriti Plimpton, and Mike Schultz for allowing the use of grape field sites and their valuable assistance with coordinating experimentation.

S.E.D. is the corresponding author. E-mail: dixonse@umsystem.edu.

This is an open access article distributed under the CC BY-NC-ND license (https://creativecommons. org/licenses/by-nc-nd/4.0/).

https://doi.org/10.21273/HORTTECH04854-21 use of dicamba (Hartzler, 2017). The adoption of DT technology in the United States doubled during the 2 years following market introduction, with $\approx 43 \%$ of soybean acreage planted using DT technology in 2018 (U.S. Department of Agriculture Economic Research Service, 2020). When glyphosate-tolerant crops were introduced in 1996, the adoption of the technology for soybean reached $96 \%$ in the United States within a decade (Dill et al., 2008). If the adoption of DT technology follows the trend observed for glyphosate-tolerant soybean, then most of the soybean acreage in the United States will constitute potential sites for dicamba applications.

In Missouri, soybeans are a leading agricultural commodity, with more than 5.4 million acres planted in 2020 (U.S. Department of Agriculture, National Agricultural Statistics Service, 2020). The proximity of DT soybean to sensitive crops such as grapes (Vitis sp.) can be problematic when dicamba is applied. In 2017, Missouri had more than 1700 acres of grape production. The majority of these are wine grapes and are valued at more than $\$ 4.28$ million as a raw commodity alone (U.S. Department of Agriculture, National Agricultural Statistics Service, 2020) with an estimated total economic impact of $\$ 3.2$ billion (Dunham, 2020). During the first growing season, following the approval by the U.S. Environmental Protection Agency (EPA) of postemergence use of dicamba for new DT crops, the Missouri Department of Agriculture received complaints of suspected dicamba injury to more than 130 acres of grapevine by Oct. 2017 (Bradley, 2017).

Grapevines are highly sensitive to synthetic auxin herbicides, and the effects can be long-lasting. Greenhouse studies of potted plants provide some insight into vegetative grapevine

\begin{tabular}{llll}
\hline $\begin{array}{l}\text { Units } \\
\text { To convert U.S. to SI, } \\
\text { multiply by }\end{array}$ & U.S. unit & SI unit & $\begin{array}{l}\text { To convert SI to U.S., } \\
\text { multiply by }\end{array}$ \\
\hline 0.4047 & acre(s) & $\mathrm{ha}$ & 2.4711 \\
29,574 & $\mathrm{fl} \mathrm{oz}$ & $\mu \mathrm{L}$ & $3.3814 \times 10^{-5}$ \\
29.5735 & $\mathrm{fl} \mathrm{oz}$ & $\mathrm{mL}$ & 0.0338 \\
0.3048 & $\mathrm{ft}$ & $\mathrm{m}$ & 3.2808 \\
3.7854 & gal & $\mathrm{L}$ & 0.2642 \\
9.3540 & gal $/ \mathrm{acre}$ & $\mathrm{L} \cdot \mathrm{ha}^{-1}$ & 0.1069 \\
2.54 & inch $(\mathrm{es})$ & $\mathrm{cm}$ & 0.3937 \\
25.4 & inch $(\mathrm{es})$ & $\mathrm{mm}$ & 0.0394 \\
1.1983 & $\mathrm{lb} / 100 \mathrm{gal}$ & $\mathrm{g} \cdot \mathrm{L}^{-1}$ & 0.8345 \\
1.1209 & $\mathrm{lb} / \mathrm{acre}$ & $\mathrm{kg} \cdot \mathrm{ha}^{-1}$ & 0.8922 \\
1 & $\mathrm{micron}(\mathrm{s})$ & $\mu \mathrm{m}$ & 1 \\
0.0254 & $\mathrm{mil}(\mathrm{s})$ & $\mathrm{mm}$ & 39.3701 \\
1.6093 & $\mathrm{mph}$ & $\mathrm{km} \cdot \mathrm{h}^{-1}$ & 0.6214 \\
28.3495 & $\mathrm{oz}$ & $\mathrm{g}$ & 0.0353 \\
70.0532 & $\mathrm{oz} / \mathrm{acre}$ & $\mathrm{g} \cdot \mathrm{ha}^{-1}$ & 0.0143 \\
1 & $\mathrm{ppb}$ & $\mathrm{ng} \cdot \mathrm{mL}^{-1}$ & 1 \\
1 & $\mathrm{ppm}$ & $\mathrm{mg} \cdot \mathrm{L}^{-1}$ & 1 \\
6.8948 & $\mathrm{psi}$ & $\mathrm{kPa}$ & 0.1450 \\
$\left({ }^{\circ} \mathrm{F}-32\right) \div 1.8$ & ${ }^{\circ} \mathrm{F}$ & ${ }^{\circ} \mathrm{C}$ & $\left({ }^{\circ} \mathrm{C} \times 1.8\right)+32$ \\
& & &
\end{tabular}


response to dicamba. As little as 7.59 $\mathrm{g} \cdot \mathrm{ha}^{-1}$ dicamba applied to rooted cuttings of 'Frontenac' hybrid grapevine (Vitis vinifera $\times$ native North American Vitis species) resulted in a $50 \%$ reduction in vine length at $28 \mathrm{~d}$ after treatment (DAT) (Knezevic et al., 2018). Visible injury observations ranged from $50 \%$ injury for 'Frontenac' grapevine exposed to $9.13 \mathrm{~g} \cdot \mathrm{ha}^{-1}$ dicamba (Knezevic et al., 2018) to $47 \%$ injury at 42 DAT for grapevines exposed to 19 $\mathrm{g} \cdot \mathrm{ha}^{-1}$ dicamba (Mohseni-Moghadam et al., 2016). Mohseni-Moghadam et al. (2016) found that only $1.9 \mathrm{~g} \cdot \mathrm{ha}^{-1}$ dicamba reduced shoot length by $13 \%$ at 42 DAT when averaged across six cultivars. The response of fruiting French-American hybrids to dicamba is of particular interest to Missouri growers because hybrids are the predominant cultivars grown.

The movement of dicamba to areas with sensitive grapevines may occur via particle drift or vapor drift. Particle drift is a function of the spray droplet size, which is influenced by nozzle type, adjuvant use, spray volume, and boom height (Felsot et al., 2010). When released into the environment, factors such as wind speed, relative humidity, and air stability influence the fate of the droplets (Felsot et al., 2010). Before DT technology, because of the extreme sensitivity of nontolerant soybeans, dicamba use for soybeans was restricted to preplant applications. Postemergence applications for DT soybean later in the growing season are likely to be subject to higher air temperatures, which favor increased volatility (Behrens and Lueschen, 1979). The active form of dicamba is an acid with relatively high vapor pressure, resulting in volatilization at increasing air temperatures (Hartzler, 2017). Since its introduction in 1962, dicamba has undergone formulation changes to reduce volatility (Mueller et al., 2013). The most recent formulations of dicamba for use on DT soybean are significantly less volatile than previous formulations (Gavlick et al., 2016). However, at field use rates, dicamba has been recovered from air samplers up to $96 \mathrm{~h}$ after spray applications to tolerant crops (Bish et al., 2019).

The success of DT crop technologies will depend, in large part, on the impact of off-target movement to sensitive crops. Grapes are an important commodity in Missouri, as well as within the United States. However, few published data are available regarding the response of fruit-bearing grapevines to dicamba, including reproductive responses of berry development and yield. The objective of this study was to determine the effects of dicamba on hybrid grapevine, 'Vidal blanc', over a 2 -year period after exposure via simulated particle drift or vapor drift.

\section{Materials and methods}

Drift simulation. Field experiments were established at three Missouri locations: Rocheport in 2017 (lat. $38^{\circ} 58^{\prime} 09.1^{\prime \prime} \mathrm{N}$, long. $92^{\circ} 31^{\prime} 20.4^{\prime \prime} \mathrm{W}$ ), Augusta in 2018 (lat. $38^{\circ} 35^{\prime} 36.6^{\prime \prime} \mathrm{N}$, long. $90^{\circ} 52^{\prime} 03.4^{\prime \prime} \mathrm{W}$ ), and Excelsior Springs (lat. $39^{\circ} 18^{\prime} 57.7^{\prime \prime} \mathrm{N}$, long. $94^{\circ} 12^{\prime} 12.2^{\prime \prime} \mathrm{W}$ ) in 2018. Each location was a commercial production vineyard, and selected grapevines were all 'Vidal blanc' hybrid grapevines established for at least 7 years. Vines had been spurpruned and trellised to two cordons per vine on a single 6 - $\mathrm{ft}$ wire, except for Excelsior Springs, which included vines trellised to two cordons per vine on a 5 -ft vertical shoot positioning system. Insecticides and fungicides were applied at regular intervals according to the established management plan for each vineyard (Beckerman et al., 2021). Bud and shoot counts were not standardized before the initiation of research. Vines were balanced pruned, either by hand or mechanically. Vines were not irrigated at any of the three study locations. Soil types included Winfield silt loam (fine-silty, mixed, superactive, mesic Oxyaquic Hapludalf) at both Rocheport and Augusta with $2.4 \%$ organic matter (both) and $\mathrm{pH}$ values of 5 and 5.9 , respectively. The soil type at Excelsior Springs was a Knox silt loam (fine-silty, mixed, superactive, mesic Mollic Hapludalf) with $3.7 \%$ organic matter and a $\mathrm{pH}$ value of 6.4. The organic matter content was determined from field samples using the loss on ignition method (Heiri et al., 2001) for organic matter determination after heating to $360^{\circ} \mathrm{C}$ (Grieve Corp., Round Lake, IL). Soil $\mathrm{pH}$ was reported as salt $\mathrm{pH}$ 1:1 measured in $0.01 \mathrm{M}$ calcium chloride solution (Burt, 2014) (Accumet; Thermo Fisher Scientific, Waltham, MA).

Each plot consisted of two adjacent vines of similar vigor selected at the beginning of the season soon after budbreak. Grapevines were exposed to two rates of particle drift or volatilized dicamba at two stages of phenological development (Table 1). "Flowering" treatments were applied during Eichhorn-Lorenz (E-L) stages 20 to 26 (Coombe, 1995), except at Augusta, which was treated at E-L stage 27 due to the rapid progression of flowering in 2018. "Fruit set" treatments were applied during E-L stages 27 to 29. Particle drift treatments were applied over the top of the grape canopy using a carbon dioxide-pressurized backpack sprayer and 4 - $\mathrm{ft}$ boom calibrated to deliver $140 \mathrm{~L} \cdot \mathrm{ha}^{-1}$ at $165 \mathrm{kPa}$ through two flat fan nozzles (8004; TeeJet Technologies, Wheaton, IL). Rates for particle drift treatments included 81 and $161 \mathrm{ppm}$ dicamba as a solution, which are equivalent to $2 \%$ and $4 \%$ of the $0.5 \mathrm{lb} /$ acre recommended use rate (Table 1). Particle drift of dicamba included a drift reduction agent (Class Act Ridion; WinField Solutions, St. Paul, MN) at $1 \%$ by volume. Concentrations were selected based on previous research and intended to elicit a visible response, but not plant death. To minimize off-target movement, a fabric shield attached to a frame was held in place behind spray applications, and applications were made when wind speeds were less than $7 \mathrm{mph}$. Nontreated grapevines were included as a control for dicamba spray applications.

Vapor drift of dicamba was simulated by applying the diglycolamine salt formulation of dicamba (BASF Corp., Research Triangle Park, NC) to Mexico silt loam (fine, smectitic, mesic Vertic Epiaqualf) soil for reproducibility across site-years. Soil was standardized across sites because digging soil from vineyards would have disturbed groundcover (maintained as mowed existing vegetation) as well as would have potentially introduced factors that influence dicamba volatilization from the soil surface (Oseland et al., 2020). Flats of soil were watered to field capacity $\mathrm{l} \mathrm{d}$ before treatment. Dicamba was applied at rates equivalent to 0.5 and $1.0 \mathrm{lb} /$ acre (Table 1) to soil in polyvinyl greenhouse flats $(10 \times 20$ inches $)$ using a handheld spray bottle (ACE, Oak Brook, IL) immediately before treatment. Flats of soil were treated at least $30 \mathrm{ft}$ away from the experimental site, wrapped in plastic sheeting for transport through the vineyard, and 


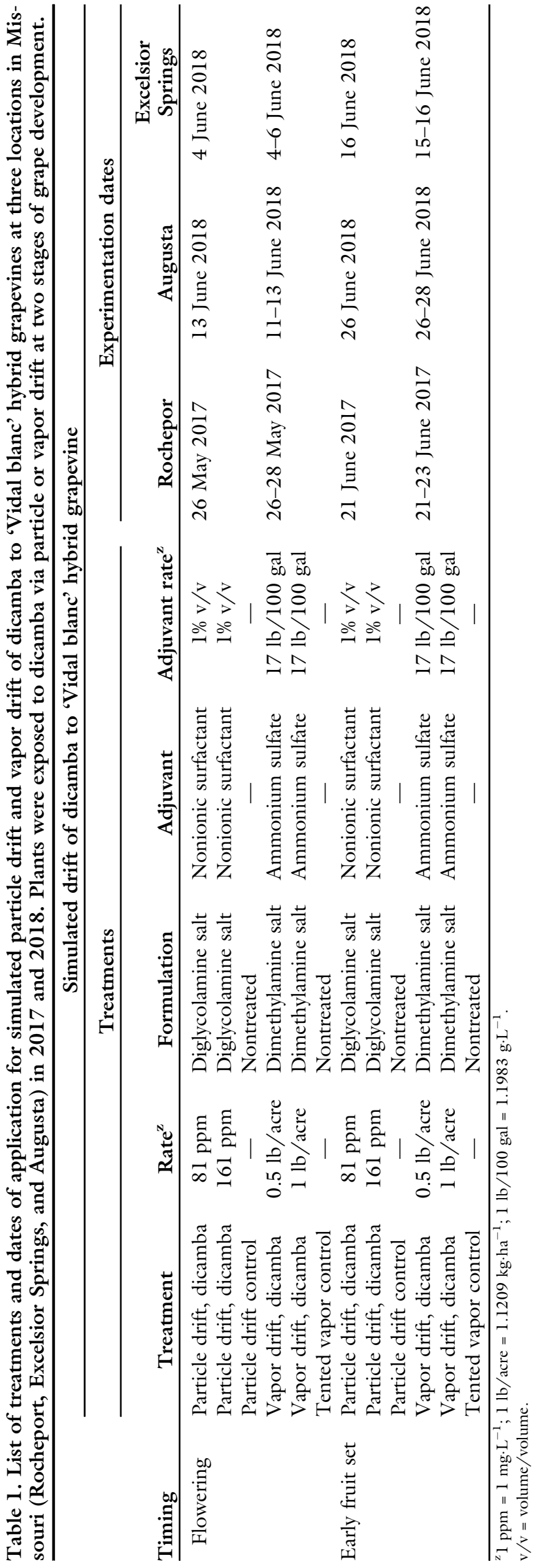

placed in preconstructed tents. Tents (Fig. 1) measuring $12 \mathrm{ft}$ (length) $\times$ $8 \mathrm{ft}$ (width) $\times 12 \mathrm{ft}$ (height) were constructed over experimental plots using polyvinyl pipe frames (JM Eagle, Columbia, MO) covered with nonagricultural-grade, 6-mil polyethylene sheeting (HDX, Atlanta, GA). Tents were in place for $48 \mathrm{~h}$ after placement of soil flats, except for the early fruit set timing at Excelsior Springs. For that treatment, tents were removed at $24 \mathrm{~h}$ to protect grapevines from heat injury when ambient temperatures increased to $96^{\circ} \mathrm{F}$. After the period of exposure, dicamba-treated soil was placed into plastic bags and sealed, and the tents and soil were removed from the vineyard. Nontreated controls for vapor drift of treatments included plots covered in tents, but without the addition of soil flats. Tented control plots for vapor treatments were distinct from particle drift controls, which were uncovered for the duration of the study.

Data collection. Data were collected throughout the growing season. The frequency of dicamba injury of grape foliage was assessed every other week after treatment by randomly selecting four shoots per plot and noting injury symptoms. The method used to quantify dicamba injury in this study estimated the prevalence of injury symptoms in all actively growing shoots. Because dicamba is readily translocated to meristematic regions (Chang and Vanden Born, 1971), injury was estimated by the presence (marked as one) or absence (marked as zero) of leaf cupping and feathering injury symptoms on the newest 10 leaves of randomly selected shoots (Fig. 2). Using this method, plots were assigned to one of five levels describing the prevalence of symptoms across the grape canopy from 0 to $4(0=$ no symptoms and $4=$ all randomly selected shoots showing injury). Although this method may be limited in its ability to describe more severe injury (i.e., epinasty or necrosis), it is important to note that these symptoms were not observed during this study.

In September of each year, grapes were hand-harvested, and yield was recorded per plot (two grapevines). During veraison, 10 berries per plot were collected from multiple grape clusters and frozen at $0{ }^{\circ} \mathrm{C}$ for later analysis of the TSS content using a 


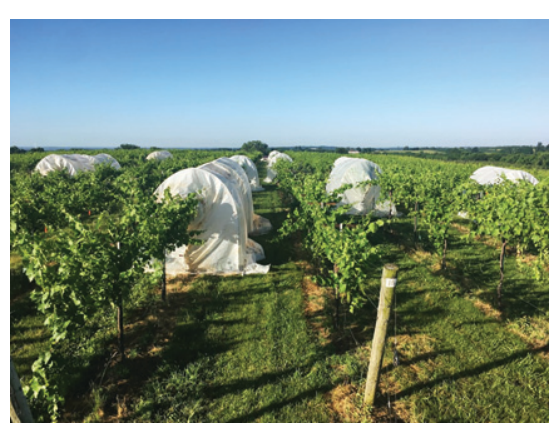

Fig. 1. A photograph of Excelsior Springs, MO, in 2018, of simulated dicamba drift plots of 'Vidal blanc' hybrid grapevines including tents for exposure to dicamba as a vapor from trays of treated soil. Fruiting grapevines were exposed to dicamba via simulated particle or vapor drift at two stages of grape development. Tents for exposure to dicamba as vapor as well as tented control plots (grapevines in tents without herbicide) were in place for 24 to $48 \mathrm{~h}$, dependent on ambient temperature, which ranged from 80 to $95{ }^{\circ} \mathrm{F}(26.7$ to $35.0^{\circ} \mathrm{C}$ ) across three site-years.

refractometer (Thermo Fisher Scientific). The small sample size for TSS measurements was chosen to minimize impacts on grape yield. Berries were allowed to thaw and were homogenized before measurements of the TSS content of grape must. Values were recorded as ${ }^{\circ}$ Brix, which correspond to $\mathrm{l} \mathrm{g}$ sucrose per $100 \mathrm{~g}$

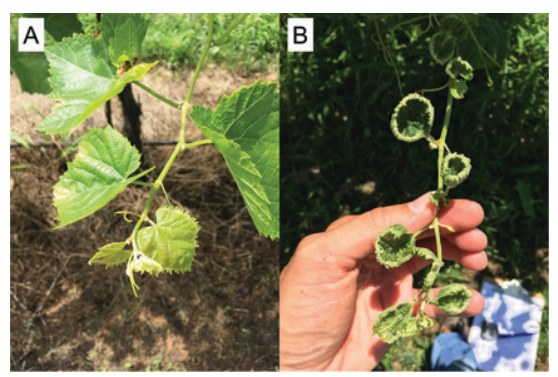

Fig. 2. Representative photographs of an uninjured 'Vidal blanc' hybrid grapevine shoot (A) and a shoot with dicamba injury symptoms after simulated particle drift (B). At three locations in Rocheport, Excelsior Springs, and Augusta, MO, in 2017 and 2018 , fruiting grapevines were exposed to dicamba as simulated particle drift or vapor drift at two stages of grape development. Injury was estimated by the presence (marked as one) or absence (marked as zero) of leaf cupping and/or feathering symptoms on the newest 10 leaves of randomly selected shoots. of solution. During harvest, a sample of 60 berries was collected across all grape clusters. Of this sample, 10 berries were used for harvest TSS measurement and 50 berries were frozen at $0{ }^{\circ} \mathrm{C}$ for later estimation of dicamba residue in grape must.

In 2018, vapor estimation tents (VETs) were used to collect air samples for the estimation of dicamba vapor released from soil. VETs were freestanding and did not enclose grape vines, but they were established adjacent to the 'Vidal blanc' vineyard block at the field edge. VETs were the same size as treatment tents and exposed to the same treatments as tents that enclosed grapevines. Soil-filled trays treated with dicamba at 0.5 and 1.0 $\mathrm{lb} / \mathrm{acre}$ and air samplers (Airchek Touch; SKC, Eighty Four, PA) were placed inside tents when experimentation began. Air samplers operated at a flow rate of $2 \mathrm{~L} \cdot \mathrm{min}^{-1}$ for $30 \mathrm{~min}$ at 4 to 8 -h intervals throughout the treatment period (24-48 h). Samples were not taken from experimental tents to avoid the release of dicamba vapor. Air from VETs was drawn through polyurethane foam (PUF) filters placed in tapered-end glass tubes connected to the pump via flexible airline tubing. Air samplers were placed on the ground within tents $\approx 3 \mathrm{ft}$ from the treated soil flat. Glass tubes containing PUF filters were set $\approx \mathrm{l} \mathrm{ft}$ above the ground using a wire stand and positioned away from the soil flat within the tent. Separate pumps and apparatus were used for each rate of dicamba. PUF filters were changed before and immediately after each 30-min sampling period. PUF filters were wrapped in aluminum foil, sealed in plastic bags, and stored at $0{ }^{\circ} \mathrm{C}$ before methanol extraction for high-performance liquid chromatography (HPLC) analysis.

For the HPLC analysis of PUF filters, dicamba was quantified as $\mathrm{ng} \cdot \mathrm{mL}^{-1}$ from methanol extractions of PUF filters using $20 \mathrm{~mL}$ of HPLCgrade methanol (Thermo Fisher Scientific). The solution was passed through a $0.2-\mu \mathrm{m}$ membrane filter and analyzed via HPLC tandem mass spectrometry using an HPLC system (Alliance 2695; Waters Corp., Milford, MA) coupled with a triple-quadrupole mass spectrometer (Acquity TQ, Waters Corp.). Compounds were chromatographically separated by a reverse-phase column $[100 \times 4.6 \mathrm{~mm} ; 2.6-\mu \mathrm{m}$ particle size
(Kinetex C18; Pehnomenex, Torrance, CA)]. Concentrations were reported as ng. $\mathrm{mL}^{-1}$ (Fig. 3 ) and corrected for the weight of methanol extracted from the PUF filter. Duplicates were made from each PUF filter methanol extraction and analyzed independently.

To evaluate grapes for the presence of dicamba residue, grape must was obtained from samples comprising 50 berries collected at harvest and immediately frozen. A blender (Toastmaster, Englewood, $\mathrm{CO}$ ) was used to homogenize grape samples. Between samples, the glass blender and blade were triple-rinsed with deionized water, followed by a triple rinse of acetone. After homogenization, samples were refrozen at $0^{\circ} \mathrm{C}$ until extraction. The quick, easy, cheap, effective, rugged, and safe (QuEChERS) method (Anastassiades et al., 2003), as modified by Lehotay et al. (2010), was used to extract dicamba from homogenized

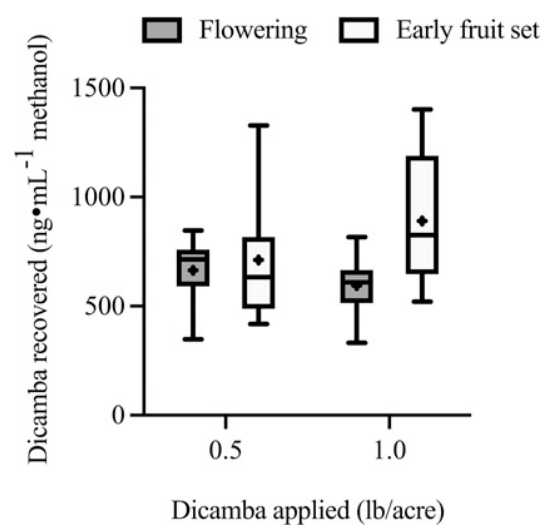

Fig. 3. Dicamba recovered from air samples taken from tents without grapevines for estimation of volatilized herbicide during experimentation at Excelsior Springs and Augusta, MO, in 2018. The effect of site-year $(P=$ 0.579 ) and rate of herbicide applied $(P=0.545)$ to soil for grape exposure to dicamba vapor were not significant. The timing of application was significant $(P=0.01)$. Data are from dicamba recovered from methanol extraction of polyurethane-foam air filters and analyzed using highperformance liquid chromatography mass spectrometry. Boxes extend from the 25 th percentile to the 75 th percentile of the distribution for each group. The horizontal line in the middle of the box indicates the median; the "+" symbol denotes the mean. Vertical lines extend to the minimum and maximum values for each group. $1 \mathrm{lb} /$ acre $=1.1209$ $\mathrm{kg} \cdot \mathrm{ha}^{-1} ; \mathrm{lng} \cdot \mathrm{mL}^{-1}=1 \mathrm{ppb}$. 
must samples. A 10-mL aliquot of homogenized must was transferred into a 50-mL Falcon tube (Thermo Fisher Scientific) with $300 \mu \mathrm{L}$ of $5 \mathrm{~N}$ sodium hydroxide solution (Thermo Fisher Scientific) and vortexed for $1 \mathrm{~min}$. After $30 \mathrm{~min}, 300 \mu \mathrm{L}$ of $5 \mathrm{~N}$ sulfuric acid solution (Thermo Fisher Scientific) and $10 \mathrm{~mL}$ of acetonitrile were added; then, the solution was vortexed for $1 \mathrm{~min}$. Salts, including $4 \mathrm{~g}$ magnesium sulfate (Thermo Fisher Scientific), 1 g sodium chloride (Thermo Fisher Scientific), 1 g trisodium citrate dihydrate (SigmaAldrich, St. Louis, MO), and $0.5 \mathrm{~g}$ disodium citrate sesquihydrate (SigmaAldrich), were added and the mixture was vortexed for $1 \mathrm{~min}$. After centrifugation for $5 \mathrm{~min}$ at $1006 \mathrm{~g}_{\mathrm{n}}$, the supernatant was removed and passed through a $0.2-\mu \mathrm{m}$ membranous filter.

A dicamba residue analysis was performed using the same HPLC mass spectrometry system as that previously described. For must samples, the mobile phase consisted of $10 \mathrm{~mm}$ ammonium acetate and $0.1 \%$ formic acid in water and $100 \%$ acetonitrile. The gradient conditions were 0 to $0.5 \mathrm{~min}$ and $2 \%$ acetonitrile, 0.5 to $7 \mathrm{~min}$ and $2 \%$ to $80 \%$ acetonitrile, 7 to $9 \mathrm{~min}$ and $80 \%$ to 98\% acetonitrile, 9 to $10 \mathrm{~min}$ and $2 \%$ acetonitrile, and 10 to $15 \mathrm{~min}$ and $2 \%$ acetonitrile at a flow rate of $0.5 \mathrm{~mL}$. $\mathrm{min}^{-1}$. The system was operated with electrospray ionization in the negative ion mode with a capillary voltage of 1.5 $\mathrm{kV}$. The ionization source was programmed at $150^{\circ} \mathrm{C}$ and the desolvation temperature was programmed at $750^{\circ} \mathrm{C}$. The ion $\mathrm{m} / \mathrm{z} 174.72[\mathrm{M}-\mathrm{H}-$ $\mathrm{COO}]^{-}$was used for quantification of dicamba. Dicamba was added to homogenous must samples at concentrations equivalent to $125,200,250,500$, or $2000 \mathrm{ng} \cdot \mathrm{mL}^{-1}$ and extracted using the QuEChERS method to determine extraction efficiency. Samples were analyzed using previously described methods and quantified using standard concentrations of 10 to $1000 \mathrm{ng} \cdot \mathrm{mL}^{-1}$ dicamba added to must samples. From treated samples, we determined that $85 \%$ to $100 \%$ dicamba was consistently recovered using the QuEChERS method. The lower limit of detection (LOD) was determined using these same standard concentrations, and the LOD for dicamba in must samples was set to $10 \mathrm{ng} \cdot \mathrm{mL}^{-1}$.

Data Analysis. The experimental design was a two-factor factorial (herbicide application and timing) arranged as a randomized complete block. For each measured variable, data were averaged from both vines within a plot to form the experimental unit. For all data, analyses were performed using a mixed model procedure (PROC GLIMMIX) in SAS (version 9.4; SAS Institute, Cary, NC) with the method and rate of dicamba delivery (treatment) and timing of exposure (timing) as fixed independent factors to distinguish effects that may have been dependent on the phenological stage in which grapevines were exposed. Block was included in models as a random variable. Visible injury data were transformed with a logit link using a binomial distribution in SAS using PROC GLMMIX. Means for treatments were separated at $\alpha=0.05$ using Tukey's honestly significant difference (HSD) test and significant main effects were identified. When data were combined across site-years, data were first examined for nonsignificant interactions among the fixed effects of treatment, timing, and site-year.

\section{Results and discussion}

VAPOR estimation. Dicamba recovery from the air inside VETs (without grapevines) provided some insight into the range of possible concentrations of dicamba to which grapevines were exposed (Fig. 3). The concentration of dicamba from air samples was not different between sites in $2018(P=0.579)$, and an interaction was not observed between the rate of dicamba applied to soil (0.5 and 1.0 $\mathrm{lb} / \mathrm{acre})$ and the experimental location $(P=0.823)$. No significant difference was found between the two application rates to soil $(P=0.545)$, with mean values of 680 and $694 \mathrm{ng} \cdot \mathrm{mL}^{-1}$ dicamba recovered from the rates of 0.5 and 1.0 $\mathrm{lb} / \mathrm{acre}$, respectively. However, the timing of dicamba exposure was significant $(P=0.01)$, with more dicamba recovered at early fruit set, likely because of warmer air temperatures during that application timing. Dicamba concentrations recovered from individual samples ranged from 332 to 1402 $\mathrm{ng} \cdot \mathrm{mL}^{-1}$, with a mean of $629 \mathrm{ng} \cdot \mathrm{mL}^{-1}$ dicamba recovered during flowering and a mean of $801 \mathrm{ng} \cdot \mathrm{mL}^{-1}$ recovered during early fruit set. Because of the method of air sampling used during this study, dicamba concentrations recovered almost certainly represent recovery of the volatilized herbicide.

The concentration of volatilized dicamba required to induce injury in exposed sensitive crops is not known for grapevine. A manipulative field study with crops enclosed in hoop houses reported vaporized 2,4-dichlorophenoxyacetic acid (2,4-D) at 1 $\mathrm{ng} \cdot \mathrm{mL}^{-1}$ was sufficient to induce injury symptoms (Weigle et al., 1970). For dicamba, Bish et al. (2019) recovered up to $25 \mathrm{ng} \cdot \mathrm{m}^{-3}$ from ambient air samples in a field study after an application of dicamba as the diglycolamine salt to tolerant soybean. When dicamba was detected up to $72 \mathrm{~h}$ after an application to DT soybean, the authors concluded that the presence of dicamba in air samples was attributable to recovery of the volatilized herbicide (Bish et al., 2019). During our study, exposure to volatilized dicamba initiated a range of visible injury symptoms.

INJURY SYMPTOMs. The concentration of dicamba required for development of injury symptoms in grapevines is very low. In 2017, the same year when the Missouri Department of Agriculture received complaints of suspected off-target movement of dicamba to more than 130 acres of grapevines (Bradley, 2017), an unexpected level of background injury at Rocheport (Table 2) was recorded for control plots; it was believed to have originated from an application in neighboring DT soybean. All treatments during this site-year displayed injury symptoms. Despite the injury to nontreated controls, grapevines exposed to dicamba particle drift had a greater frequency of injured shoots, with a mean of 3.5 shoots with injury (out of four) for both rates of particle drift delivered during early fruit set.

At Excelsior Springs, injury symptoms were more frequent for grapevines exposed to particle drift of dicamba than to vapor drift (Table 2). As with Rocheport in 2017, a nonsignificant interaction of the main effects of treatment and timing $(P=0.32)$ suggests that vegetative injury responses at Excelsior Springs were not dependent on the phenological stage in which grapevines were exposed to dicamba. Dicamba applied as particle drift at 161 ppm resulted in the greatest injury, with a mean of 2.5 and three of four randomly selected shoots symptomatic of dicamba injury at flowering and fruit 
Table 2. Mean visual injury for three site-years during grape veraison in Missouri. 'Vidal blanc' hybrid grapevines were exposed to dicamba as simulated particle or vapor drift (treatment) at two stages of grape development (timing). Four shoots were randomly selected per plot, and injury was observed as leaf cupping and/or feathering on a single shoot. The presence of dicamba symptoms was marked as 1 and uninjured shoots were marked as 0 , yielding values ranging from 0 to $4(0$ = no symptoms; 4 = all randomly selected shoots with injury) for a single plot (two grapevines).

\begin{tabular}{|c|c|c|c|c|c|c|}
\hline \multirow[b]{4}{*}{ Treatment $^{\mathrm{z}}$} & \multicolumn{6}{|c|}{ Dicamba injury symptoms on grape shoots mean \pm SE $(0-4$ scale $)$} \\
\hline & \multirow{2}{*}{\multicolumn{2}{|c|}{$\begin{array}{c}\text { Rocheport, MO } \\
23 \text { Aug. } 2017\end{array}$}} & \multirow{2}{*}{\multicolumn{2}{|c|}{$\begin{array}{l}\text { Augusta, MO } \\
22 \text { Aug. } 2018\end{array}$}} & \multirow{2}{*}{\multicolumn{2}{|c|}{$\begin{array}{c}\text { Excelsior Springs, MO } \\
25 \text { Aug. } 2018 \\
\end{array}$}} \\
\hline & & & & & & \\
\hline & Flowering & Early fruit set & Flowering & Early fruit set & Flowering & Early fruit set \\
\hline Particle drift, $81 \mathrm{ppm}$ & $3.0 \pm 1.2 \mathrm{NS}^{\mathbf{y}}$ & $3.5 \pm 0.6 \mathrm{NS}$ & $2.0 \pm 1.4 \mathrm{bc}^{\mathrm{y}}$ & $3.8 \pm 0.5 \mathrm{ab}$ & $2.0 \pm 1.4 \mathrm{NS}$ & $2.5 \pm 0.6 \mathrm{NS}$ \\
\hline Particle drift, $161 \mathrm{ppm}$ & $2.5 \pm 1.0$ & $3.5 \pm 0.6$ & $2.8 \pm 1.0 \mathrm{ab}$ & $4.0 \pm 0.0 \mathrm{a}$ & $2.5 \pm 1.0$ & $3.0 \pm 0.0$ \\
\hline Vapor drift, $1 \mathrm{lb} /$ acre & $2.5 \pm 1.0$ & $2.3 \pm 1.7$ & $0.3 \pm 0.5 \mathrm{~cd}$ & $2.0 \pm 1.6 \mathrm{bc}$ & $2.0 \pm 1.8$ & $0.8 \pm 1.0$ \\
\hline Vapor control & $1.5 \pm 0.6$ & $2.3 \pm 0.5$ & $0.3 \pm 0.5 \mathrm{~cd}$ & $0.0 \pm 0.0 \mathrm{~d}$ & $0.0 \pm 0.0$ & $0.8 \pm 0.5$ \\
\hline \multicolumn{7}{|l|}{$P$ value } \\
\hline Treatment & & 0.0187 & & $<0.0001$ & & $<0.0001$ \\
\hline Treatment $\times$ timing & & 0.2573 & & $<0.0001$ & & 0.3200 \\
\hline
\end{tabular}

${ }^{\mathrm{z}} \mathrm{l} \mathrm{ppm}=1 \mathrm{mg} \cdot \mathrm{L}^{-1} ; \mathrm{l} \mathrm{lb} / \mathrm{acre}=1.1209 \mathrm{~kg} \cdot \mathrm{ha}^{-1}$.

${ }^{\mathrm{y}}$ Data were analyzed within the site-year using a mixed linear model. When the interaction term for main effects was significant among treatments, means were separated using Tukey's honestly significant difference test. Means followed by the same letter are not significantly different. Ns $=$ not significant at $\alpha=0.05$.

set, respectively. Grapevines exposed to vapor drift of dicamba responded with a maximum of two of four shoots displaying injury. Grapevines exposed to vapor drift of dicamba at $0.5 \mathrm{lb} / \mathrm{acre}$ at flowering had the least number of shoots with symptoms, with a mean of 0.5 of four shoots injured. Minor symptoms of dicamba injury were detected in one nontreated, tented control plot. Injury symptoms were not observed in any other particle drift and vapor drift controls.

At Augusta, there was a highly significant interaction between treatment $\times$ timing of exposure $(P<0.0001)$, likely attributable to variable injury symptoms in response to vapor drift of dicamba (Table 2). Vapor drift at flowering did not result in significant injury for either rate of dicamba applied to soil. However, when grapevines were exposed to vapor drift during early fruit set, all shoots displayed injury symptoms for the $0.5-\mathrm{lb} /$ acre rate of dicamba, whereas approximately half of shoots exposed to $1.0 \mathrm{lb} /$ acre had injury symptoms. For particle drift, injury was present on half of shoots for grapevines exposed to $81 \mathrm{ppm}$ dicamba at flowering and on all selected shoots when grapevines were exposed to 161 ppm dicamba during early fruit set. Injury was detected in one control plot at Augusta, resulting in a mean of 0.3 injured shoots for nontreated control plots tented during flowering.
At Augusta, the difference between injury responses to vapor treatments delivered at flowering and early fruit set was unexpected. The methods used for vapor drift simulation were consistent across both timings. No environmental disparities that could account for the difference were observed in the vineyard except for ambient temperature. At flowering, peak daytime temperatures over the 48-h period of vapor exposure decreased from 94 to $89^{\circ} \mathrm{F}$. There are two possible consequences of high temperatures at the onset of exposure. First, soil drying reduces pesticide volatility losses from soil (Burnside and Lavy, 1966). In addition, under these temperatures, grapevines may have closed stomata to prevent water loss, thus reducing stomatal absorption of dicamba (Knoche and Petracek, 2014; Sargent and Blackman, 1962). In contrast, during fruit set, peak ambient temperatures increased steadily over the period of exposure from 81 to $94^{\circ} \mathrm{F}$. Lower temperatures at the onset of dicamba exposure may have allowed for longer soil drying time, thus increasing dicamba vapor loss from soil (Spencer et al., 1973).

Based on visible injury responses, the data confirm grape sensitivity to plant growth regulators that has been described in previous studies. With dicamba in greenhouse studies, injury has been observed at rates as low as 1.9 $\mathrm{g} \cdot \mathrm{ha}^{-1}$ for 'Riesling', 'Chardonnay', 'Chardonel', 'Vidal blanc', and
'Traminette' hybrid grapevines when applied as a spray (Mohseni-Moghadam et al., 2016). Similarly, injury from the growth regulator 2,4-D, remained visible at 30 DAT when applied as a spray at only $1.2 \mathrm{~g} \cdot \mathrm{ha}^{-1}$ to mature grapevines (Bhatti et al., 1996).

Grape YIELD. Despite the prevalence of dicamba symptoms on grape foliage, translation to yield impacts were unclear. Within individual siteyears, significant variability in grape yield was observed within treatments as well as nontreated controls (Table 3); when data were combined across sites, no treatment effects were observed $(P=0.378)$.

At Rocheport in 2017, reductions in grape yield were associated with exposure to vapor drift of dicamba (Table 3). Mean grape yield after exposure to vapor drift of dicamba at flowering was reduced $45 \%$ compared to nontreated controls $(P=0.035)$. At early fruit set, the mean grape yield after exposure to vapor drift of dicamba was also reduced $45 \%$ compared to controls $(P=0.015)$. Despite the greater frequency of injury symptoms with particle drift of dicamba, significant yield reductions were not detected for grapevines exposed to particle drift.

At Excelsior Springs in 2018, plant vigor was high, and grape yield was highest of the three site-years. A highly significant interaction was observed between dicamba treatment $\times$ timing 
Table 3. Mean grape yield (kg) per plot (two grapevines) with standard error for Rocheport, MO in 2017; Excelsior Springs, MO and Augusta, MO, in 2018. Fruiting grapevines were exposed to dicamba as simulated particle or vapor drift of dicamba (treatment) at two stages of grape development (timing). Means followed by the same letter are not significantly different at $\alpha=0.05$ using Tukey's honestly significant difference.

\begin{tabular}{|c|c|c|c|c|c|c|}
\hline \multirow[b]{4}{*}{ Treatment $^{\mathrm{z}}$} & \multicolumn{6}{|c|}{ Grape yield by site yr (kg/plot) } \\
\hline & \multirow{2}{*}{\multicolumn{2}{|c|}{$\frac{2017}{\text { Rocheport, MO }}$}} & \multicolumn{4}{|c|}{2018} \\
\hline & & & \multicolumn{2}{|c|}{ Augusta, MO } & \multicolumn{2}{|c|}{ Excelsior Springs, MO } \\
\hline & Flowering $^{\mathrm{y}}$ & Early fruit set & Flowering & Early fruit set & Flowering & Early fruit set \\
\hline Particle drift, 81 ppm & $5.8 \mathrm{ab} \pm 1.3$ & $5.5 \mathrm{ab} \pm 1.4$ & $11.0 \mathrm{NS} \pm 4.9$ & $8.2 \mathrm{NS} \pm 4.9$ & $19.3 \mathrm{~cd} \pm 2.6$ & $24.5 \mathrm{abcd} \pm 5.1$ \\
\hline Particle drift, $161 \mathrm{ppm}$ & $4.3 \mathrm{~b} \pm 2.0$ & $7.9 \mathrm{ab} \pm 3.2$ & $12.1 \pm 7.0$ & $12.9 \pm 7.2$ & $30.3 \mathrm{a} \pm 5.5$ & $18.2 \mathrm{~d} \pm 10.0$ \\
\hline Vapor drift, $1 \mathrm{lb} /$ acre & $4.7 \mathrm{~b} \pm 1.3$ & $4.4 \mathrm{~b} \pm 1.7$ & $10.7 \pm 6.1$ & $3.6 \pm 2.0$ & $22.8 \mathrm{bcd} \pm 1.1$ & $24.9 \mathrm{abcd} \pm 0.1$ \\
\hline Vapor control & $8.5 \mathrm{a} \pm 4.1$ & $8.0 \mathrm{a} \pm 2.6$ & $5.7 \pm 3.3$ & $8.6 \pm 4.5$ & $24.4 \mathrm{abcd} \pm 6.6$ & $21.7 \mathrm{bcd} \pm 6.9$ \\
\hline \multicolumn{7}{|l|}{$P$ value } \\
\hline Treatment & & 0.0004 & & 0.1496 & & 0.3991 \\
\hline Treatment $\times$ timing & & 0.0103 & & 0.3687 & & $<0.0001$ \\
\hline
\end{tabular}

${ }_{\mathrm{z}}^{\mathrm{z}}$ Data were analyzed within the site-year using a mixed linear model. When the interaction term for main effects was significant among treatments, means were separated using Tukey's honestly significant difference test.

${ }^{\mathrm{y}} 1 \mathrm{~kg}=2.2046 \mathrm{lb} ; \mathrm{l} \mathrm{ppm}=1 \mathrm{mg} \cdot \mathrm{L}^{-1} ; \mathrm{l} \mathrm{lb} /$ acre $=1.1209 \mathrm{~kg} \cdot \mathrm{ha}^{-1}$.

Means followed by the same letter are not significantly different. Ns $=$ not significant at $\alpha=0.05$.

of grape exposure $(P<0.0001)$, with yield reductions associated with particle drift of dicamba (Table 3). After exposure to particle drift at $81 \mathrm{ppm}$ during flowering, yield was reduced by $32 \%$ relative to nontreated controls. Yield was not reduced for particle drift at $161 \mathrm{ppm}$ during flowering, and significant yield reductions were not observed for grapevines exposed to vapor drift of dicamba during flowering or early fruit set. At Augusta in 2018, significant variations both within and among treatments were observed, and no treatment differences were detected. During the season after dicamba exposure, when grape yield was evaluated at harvest, yield reductions observed during the year when grapevines were injured did not persist into the second season (data not shown). Furthermore, no significant differences for grape yield were found within or across site-years during the second season. Similarly, during the year after grape injury, no treatment differences were found when budbreak was evaluated in early spring (data not shown).

At Rocheport in 2017, and at Excelsior Springs in 2018, where significant effects were observed, yield reductions in response to dicamba were more frequent when grapevines were exposed at flowering. For Excelsior Springs, the grape yield response to $81 \mathrm{ppm}$ during flowering was consistent with results that described a $31 \%$ reduction in yield after a single application of simulated particle drift of 2,4-D at $25 \mathrm{ppm}$ applied at flowering (Ogg et al., 1991). Similar to vapor treatments at Rocheport in 2017, when volatilized 2,4-D at 1 $\mathrm{ng} \cdot \mathrm{mL}^{-1}$ was added to the ambient air in hoop houses, grape yield was reduced by at least $50 \%$ (Weigle et al., 1970). Limited data are available regarding grape yield response to dicamba. As with Augusta in 2018, Rossouw et al. (2019) found no measurable yield reductions from potted bearing 'Tempranillo' grapevines $(\mathrm{n}=45)$ in response to dicamba at $65 \mathrm{~g} \cdot \mathrm{ha}^{-1}$, a rate nearly three-times that of the highest rate of particle drift used in our study. With herbicide injury, common biotic and abiotic stresses occurring in field conditions likely exacerbate yield responses. Field and greenhouse studies with stress combinations (e.g., drought and nutrient deficiency) conclude that the presence of two or more stress conditions results in plant responses that are unique and cannot be predicted from responses to a single stress (Suzuki et al., 2014). Our data show that yield reductions after exposure to either particle drift or vapor drift of dicamba are possible; however, environmental factors likely exert a significant influence on the severity of yield responses.

Berry Maturity. Grape maturity, as measured by the accumulation of TSS in the fruit during veraison, can be delayed by dicamba. No significant siteyear $\times$ treatment interaction $(P=0.419)$ was observed for measurements of TSS (Fig. 4). Across all site-years, no treatment effects were observed when berries were collected during veraison on 8 Aug. 2018, 10 Aug. 2018, and 10 Aug. 2017 for Augusta, Excelsior Springs, and Rocheport, respectively. However, $\approx 1$ month later at harvest (12 Sept. 2018, 13 Sept. 2018, and 28 Sept. 2017 for Augusta, Excelsior Springs, and Rocheport, respectively), significant treatment effects were observed $(P=$ $0.001)$. The timing of dicamba exposure was not significant $(P=0.591)$. The mean TSS content of berries at harvest was reduced $12 \%$ compared to nontreated controls for grapevines exposed to $161 \mathrm{ppm}$ particle drift of dicamba. Although other treatment means were not significantly different using Tukey's HSD at $\alpha=0.05$, it is worth noting that berry TSS contents were lower compared with nontreated controls for all grapevines exposed to dicamba, either as particle drift or vapor drift.

Reductions in the TSS content of berries after herbicide exposure are consistent with those observed during previous research that measured a $9 \%$ reduction in the TSS of 'Concord' grape juice in response to injury from 2,4-D (Ogg et al., 1991). The potential for reduced TSS content of berries at harvest after exposure to dicamba may be higher for 'Vidal blanc' hybrid grapevine, with reductions of up to $12 \%$ measured during this study. This is in contrast to the findings of Rossouw et al. (2019), who reported no reduction in berry TSS in response to 


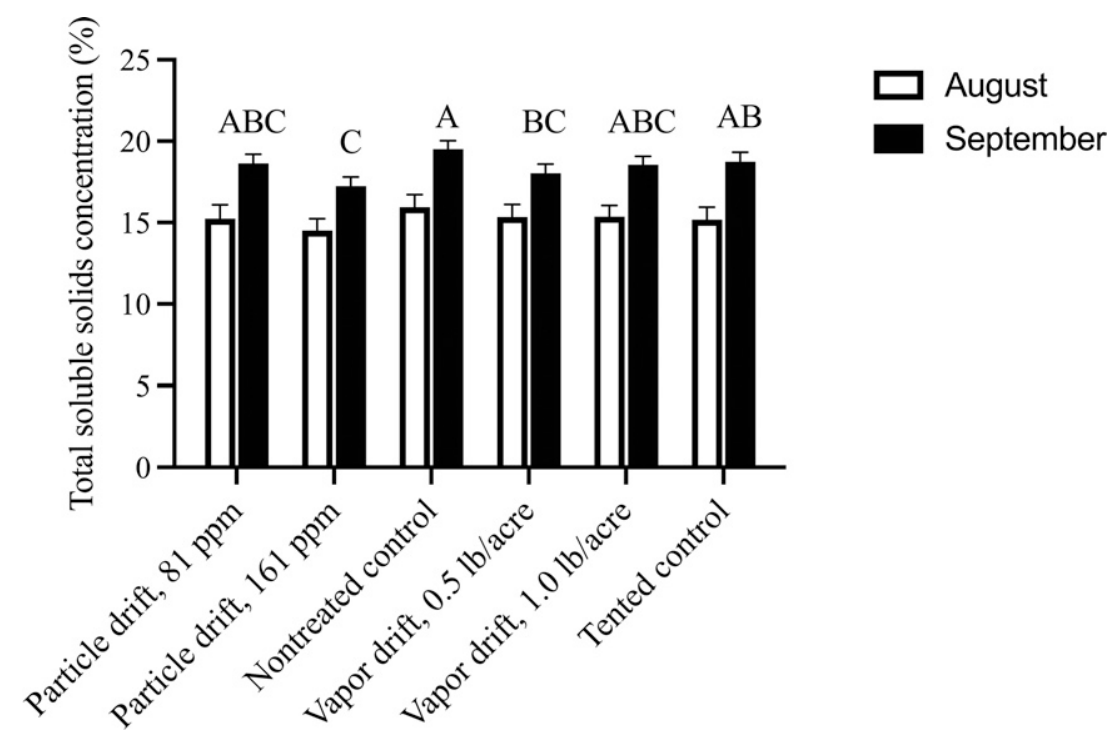

Fig. 4. Mean values of the total soluble solids (TSS) content of grape berries harvested from 'Vidal blanc' hybrid grapevine across three site-years. Plants were exposed to dicamba as simulated particle drift or vapor drift of dicamba (treatment) at two stages of grape development (timing). Ten berries were collected for measurements of TSS during veraison on 8 Aug. 2018, 10 Aug. 2018, and 10 Aug. 2017 for Augusta, Excelsior Springs, and Rocheport, MO, respectively. A subsample of 10 berries was also collected at harvest for the estimation of berry TSS on 12 Sept. 2018, 13 Sept. 2018, and 28 Sept. 2017 for Augusta, Excelsior Springs, and Rocheport, MO, respectively. No significant treatment effects were detected when berries were harvested in August. At harvest in September, the effect of timing of grape exposure to dicamba was not significant $(P=$ $0.59)$, whereas the effect of treatment was significant $(P=0.001)$. Treatment means followed by the same letter are not significantly different at $\alpha=0.05$ using Tukey's honestly significant difference test. Vertical bars indicate SE. 1 ppm $=1$ $\mathrm{mg} \cdot \mathrm{L}^{-1} ; 1 \mathrm{lb} / \mathrm{acre}=1.1209 \mathrm{~kg} \cdot \mathrm{ha}^{-1}$.

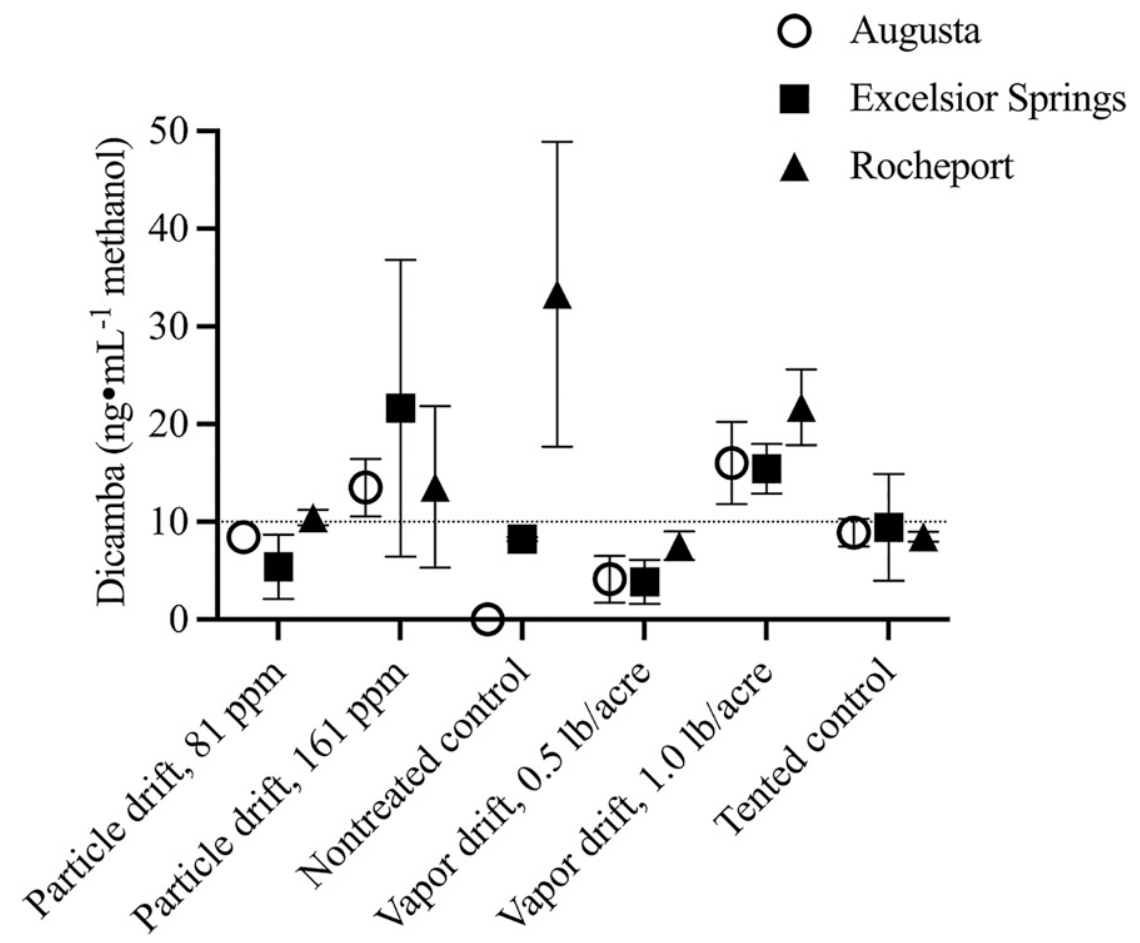

Fig. 5. Dicamba residue recovered from grape must (juice and skin) samples collected at harvest on 12 Sept. 2018, 13 Sept. 2018, and 28 Sept. 2017 for Augusta, Excelsior Springs, and Rocheport, MO, respectively. Fruiting 'Vidal blanc' hybrid grapevines were exposed to dicamba via simulated particle drift or vapor drift of dicamba (treatment) at two stages of grape development (timing). Data are from dicamba recovered from methanol-based extraction using the method described by Lehotay et al. (2010) and analyzed using high-performance liquid chromatography mass spectrometry. The limit of detection (i.e., the lowest concentration that can be reliably distinguished from zero) was determined to be $10 \mathrm{ng} \cdot \mathrm{mL}^{-1}$ and is represented by the horizontal dashed line. Symbols represent the mean of two extraction replicates. Vertical bars indicate the SEM. 1 ppm $=1$ $\mathrm{mg} \cdot \mathrm{L}^{-1} ; 1 \mathrm{lb} / \mathrm{acre}=1.1209 \mathrm{~kg} \cdot \mathrm{ha}^{-1} ; 1 \mathrm{ng} \cdot \mathrm{mL}^{-1}=1 \mathrm{ppb}$. 
dicamba applied to potted 'Tempranillo' grapevines. The absence of detectable effects during veraison in August, as was the case during this study, may complicate matters for grape producers. Winemakers can ameliorate lower berry TSS through chaptalization (i.e., the addition of sugar to unfermented grape must), which is a process that is federally legal in the United States but prohibited in California (Meloni et al., 2019). However, growers who sell the grape harvest as a raw product may incur penalties as a result of grapes with less than desirable TSS content.

DicAMba RESIDUE IN GRAPES. The EPA establishes tolerances for pesticide residues detected in agricultural commodities (U.S. Environmental Protection Agency, 2020). For dicamba, the tolerance in commodities for human consumption such as grain crops and animal products is $25 \mathrm{ppm}$. To date, no legal tolerance has been established for grapes. When homogenized grape must was evaluated for the presence of dicamba as the parent compound (3,6-dichloro-2-methoxybenzoic acid), all site-years contained dicamba residue (Fig. 5). Using dicamba standards, the lower LOD in must samples was determined to be 10 $\mathrm{ng} \cdot \mathrm{mL}^{-1}$; therefore, values less than $10 \mathrm{ng} \cdot \mathrm{mL}^{-1}$ can be interpreted as not different from zero. All control plots, except Rocheport, contained less than $10 \mathrm{ng} \cdot \mathrm{mL}^{-1}$ dicamba residue. The detection of dicamba residue in nontreated controls at Rocheport was not unexpected because injury to controls was observed.

The timing of grape exposure to dicamba was not a significant predictor of the detection of dicamba residue $(P$ $=0.72$ ). Across site-years, at least $90 \mathrm{~d}$ and up to $125 \mathrm{~d}$ elapsed between the first drift simulation and grape harvest. Residue was highest when grapevines were exposed to either $161 \mathrm{ppm}$ of particle drift or dicamba vapor from the 1.0-lb/acre soil application, with mean values of 17 and $18 \mathrm{ng} \cdot \mathrm{mL}^{-1}$, respectively. When grapevines were exposed to particle drift at $81 \mathrm{ppm}$ or dicamba vapor from a $0.5-\mathrm{lb} /$ acre soil application, dicamba residue was not different from zero, with mean values of 8 and $5 \mathrm{ng} \cdot \mathrm{mL}^{-1}$ across site-years.

The residue data are consistent with the results of field studies simulating dicamba drift with watermelon
(Citrullus lanatus); for example, Culpepper et al. (2018) reported dicamba residue in fruit tissues at harvest after an application of $2.2 \mathrm{~g} \cdot \mathrm{ha}^{-1}$ to plants $48 \mathrm{~d}$ before harvest. The quantity of dicamba observed in grapes was quite small; no one sample exceeded $70 \mathrm{ng}$. $\mathrm{mL}^{-1}$. However, without legal tolerances established by the EPA for grapes or grape products, vineyard managers should consider the potential detection of dicamba residue in fruit when responding to suspected drift events. This is the first field research of established grapevines that identifies the presence of dicamba in grape products at harvest, especially when the simulated drift event occurred up to $125 \mathrm{~d}$ before harvest.

\section{Conclusion}

Based on observations across three site-years in Missouri, the field research confirms the sensitivity of 'Vidal blanc' hybrid grapevine to dicamba as particle drift or vapor drift. During all site-years, visible symptomology persisted throughout the growing season. When significant treatment effects were observed for grape yield, yield reductions were more frequent for grapevine exposure at flowering than early fruit set. Approximately 1 month before harvest, no effects were detected in the TSS content of berries for grapevines exposed to dicamba as either particle drift or vapor drift. However, at harvest, the TSS content in fruit was reduced up to $12 \%$ compared to controls for grapevines exposed to particle drift. Delays in berry maturity and reduced TSS content of grapes have the potential to complicate harvest, marketing the harvested crop, and the winemaking process. Finally, dicamba residue was detected during all site-years and even in treatments with low visual injury, indicating that dicamba drift events to grapevines that induce minor visible injury symptoms may result in detectable residue in grape must at harvest. During this research, dicamba effects on grape yield did not persist to the following season.

\section{Literature cited}

Anastassiades, M., S.J. Lehotay, D. Štajnbaher, and F.J. Schenck. 2003. Fast and easy multiresidue method employing acetonitrile extraction/partitioning and dispersive solid-phase extraction for the determination of pesticide residues in produce. J. Assoc. Off. Agr. Chemists Intl.
86:412-431, https://doi.org/10.1093/ jaoac/86.2.412.

Beckerman, J., R. Bessin, J. Strang, C. Welty, L. Rodriguez-Salamanca, K. Athey, S. Meyer, E. Long, M. Heller-Haas, M. Lewis-Ivey, D. Lewis, C. Guedot, E. Wahle, T. Tucker, S. Wright, D. Becker, J. Hannan, C. Smigell, R. Onofre, N. Joshi, B. Bordelon, M. Babadoost, J. Patel, L. Holland, A. Klodd, and N.W. Gauthier. 2021. Midwest fruit pest management guide 2021-2022. 20 Aug. 2021. <https://ag.purdue.edu/ hla/Hort/Documents/ID-465.pdf $>$.

Behrens, R. and W.E. Lueschen. 1979. Dicamba volatility. Weed Sci. 27:486-493, https://doi.org/10.1017/s00431745000 44453 .

Bhatti, M.A., K. Al-Khatib, and R. Parker. 1996. Wine grape (Vitis vinifera) response to repeated exposure of selected sulfonylurea herbicides and 2,4-D. Weed Technol. 10:951-956, https://doi.org/ $10.1017 / \mathrm{s} 0890037 \mathrm{x} 00041075$.

Bish, M.D., S.T. Farrell, R.N. Lerch, and K.W. Bradley. 2019. Dicamba losses to air after applications to soybean under stable and nonstable atmospheric conditions. J. Environ. Qual. 48:1675-1682, https:// doi.org/10.2134/jeq2019.05.0197.

Bradley, K.W. 2017. The dicamba dilemma: Where do we go from here? 10 May 2018. $<$ https://weedscience.missouri.edu/ dicamba.cfm $>$.

Burnside, O.C. and T.L. Lavy. 1966. Dissipation of dicamba. Weeds 14:211-214, https://doi.org/10.2307/4040915.

Burt, R. (ed.). 2014. Kellogg soil survey laboratory methods manual. Soil Survey Investigations Report no. 42, Version 5. U.S. Dept. Agr., Lincoln, NE.

Chang, F.Y. and W.H. Vanden Born. 1971. Dicamba uptake, translocation, metabolism, and selectivity. Weed Sci. 19: 113-117, https://doi.org/10.1017/s00 43174500048414 .

Coombe, B.G. 1995. Growth stages of the grapevine: Adoption of a system for identifying grapevine growth stages. Austral. J. Grape Wine Res. 1:104-110, https://doi.org/ 10.1111/j.1755-0238.1995.tb00086.x.

Culpepper, A.S., L.M. Sosnoskie, J. Shugart, N. Leifheit, M. Curry, and T. Gray. 2018. Effects of low-dose applications of 2, 4-D and dicamba on watermelon. Weed Technol. 32:267-272, https://doi. org/10.1017/wet.2018.4.

Dill, G.M., C.A. CaJacob, and S.R. Padgette. 2008. Glyphosate-resistant crops: Adoption, use and future considerations. Pest Mgt. Sci. 64:326-331, https://doi. org/10.1002/ps.1501. 
Dunham, J. 2020. WineAmerica Impact. 22 Sept. 2020. <https://wineamerica. org/impact/>.

Felsot, A.S., J. Unsworth, J. Linders, G. Roberts, D. Rautman, C. Harris, and E. Carazo. 2010. Agrochemical spray drift; assessment and mitigation-A review. J. Environ. Sci. Health B 46:1-23, https://doi.org/ 10.1080/03601234.2010.515161.

Gavlick, W.K., D.R. Wright, A. MacInnes, J.W. Hemminghaus, J.K. Webb, V.I. Yermolenka, and W. Su. 2016. A method to determine the relative volatility of auxin herbicide formulations, p. 24-32. In: Pesticide formulation and delivery systems. Vol. 35. Pesticide formulations, adjuvants, and spray characterization in 2014. Amer. Soc. Testing Materials Intl., West Conshohocken, PA, https://doi.org/10.1520/ STP158720150006.

Hartzler, B. 2017. Dicamba: Past, present, and future. 20 Aug. 2021. <https://lib.dr. iastate.edu/icm/2017/proceedings/12/>, https://doi.org/10.31274/icm-180 809-241.

Heap, I. 2019. International herbicide-resistant weed database. 6 Mar. 2017. <http:// www.weedscience.org/Home.aspx $>$.

Heiri, O., A.F. Lotter, and G. Lemcke. 2001. Loss on ignition as a method for estimating organic and carbonate content in sediments: Reproducibility and comparability of results. J. Paleolimnol. 25:101-110, https://doi.org/10.1023/a:1008119611 481.

Knezevic, S.Z., O.A. Osipitan, and J.E. Scott. 2018. Sensitivity of grape and tomato to micro-rates of dicamba-based herbicides. J. Hort. 5:2376-2354, https://doi.org/ $10.4172 / 2376-0354.1000229$.

Knoche, M. and P.D. Petracek. 2014. Foliar uptake of PGRs: Barriers, mechanisms, model systems, and factors. Acta
Hort. 1042:125-141, https://doi.org/ 10.17660/actahortic.2014.1042.16.

Lehotay, S.J., K.A. Son, H. Kwon, U. Koesukwiwat, W. Fu, K. Mastovska, E. Hoh, and N. Leepipatpiboon. 2010. Comparison of QuEChERS sample preparation methods for the analysis of pesticide residues in fruits and vegetables. J. Chromatography 1217:2548-2560, https://doi. org/10.1016/j.chroma.2010.01.044.

Meloni, G., K. Anderson, K. Deconinck, and J. Swinnen. 2019. Wine regulations. Appl. Econ. Perspect. Policy 41:620-649, https://doi.org/10.1093/aepp/ppz025.

Mohseni-Moghadam, M., S. Wolfe, I. Dami, and D. Doohan. 2016. Response of wine grape cultivars to simulated drift rates of 2, 4-D, dicamba, and glyphosate, and 2, 4-D or dicamba plus glyphosate. Weed Technol. 30:807-814, https://doi. org/10.1614/wt-d-15-00106.1.

Mueller, T.C., D.R. Wright, and K.M. Remund. 2013. Effect of formulation and application time of day on detecting dicamba in the air under field conditions. Weed Sci. 61:586-593, https://doi.org/ 10.1614/ws-d-12-00178.1.

Ogg, A.G., M.A. Ahmedullah, and G.M. Wright. 1991. Influence of repeated applications of 2,4-D on yield and juice quality of concord grapes (Vitis labruscana). Weed Sci. 39:284-295, https://doi.org/ $10.1017 /$ s0043174500071629.

Oseland, E., M. Bish, L. Steckel, and K. Bradley. 2020. Identification of environmental factors that influence the likelihood of off-target movement of dicamba. Pest Manag. Sci. 76:3282-3291, https:// doi.org/10.1002/ps.5887.

Rossouw, G.C., B.P. Holzapfel, S.Y. Rogiers, J.C. Gouot, and L.M. Schmidtke. 2019. Repercussions of four herbicides on reproductive and vegetative development in potted grapevines. Austral. J. Grape Wine Res. 25:316-326, https://doi.org/ 10.1111/ajgw.12395.

Sargent, J.A. and G.E. Blackman. 1962. Studies on foliar penetration: I. Factors controlling the entry of 2, 4-dichlorophenoxyacetic acid. J. Expt. Bot. 13:348-368, https://doi.org/10.1093/jxb/13.3.348.

Suzuki, N., R.M. Rivero, V. Shulaev, E. Blumwald, and R. Mittler. 2014. Abiotic and biotic stress combinations. New Phytol. 203:32-43, https://doi.org/10.1111/ nph.12797.

Spencer, W.F., W.J. Farmer, and M.M. Claith. 1973. Pesticide volatilization. In: F.A. Gunther (ed.). Residue reviews. Vol. 49. Springer, New York, NY, https:// doi.org/10.1007/978-1-4613-9377-1_1.

U.S. Department of Agriculture, Economic Research Service. 2020. The use of genetically engineered dicamba-tolerant soybean seeds has increased quickly, benefiting adopters but damaging crops in some fields. 22 Sept. 2020. <https://www.ers.usda. gov/amber-waves/2019/october/the-useof-genetically-engineered-dicamba-tolerantsoybean-seeds-has-increased-quicklybenefiting-adopters-but-damaging-crops-insome-fields $/>$.

U.S. Department of Agriculture, National Agricultural Statistics Service. 2020. State agriculture overview: Missouri. 10 Dec. 2020. <https://www.nass.usda.gov/Quick_ Stats/Ag_Overview/stateOverview.php? state $=$ MISSOURI $>$.

U.S. Environmental Protection Agency. 2020. Tolerances and exemptions for pesticide residues in food. 36 C.F.R. 40 $\$ 180.227$.

Weigle, J.L., E.L. Denison, and C.H. Sherwood. 1970. 2,4-D as an air pollutant: Effects on market quality of several horticultural crops. HortScience 5:213-214. 